\title{
Cinderella across Disciplines
}

Martine Hennard Dutheil de la Rochère, Gillian Lathey \& Monika Woźniak, eds. 2016. Cinderella across Cultures: New Directions and Interdisciplinary Perspectives. Detroit: Wayne State University Press. 421 pp. ISBN 978-0-8143-4155-1

DOI: 10.21066/carcl.libri.2017-06(02).0009

Cinderella across Cultures: New Directions and Interdisciplinary Perspectives is a collection of papers situated at the intersection of fairy-tale and translation studies, edited by Martine Hennard Dutheil de la Rochère, Gillian Lathey, and Monika Woźniak, and published in the renowned Wayne State University Press Series in Fairy-Tale Studies. In line with the editors' expertise in the fields of translation and literary studies, the selection of papers included in the collection is reliable, the organisation of papers in the book motivated, while the introductory chapter is both informative and innovative. The approaches adopted in this book are best summarised in the editors' wish to avoid two possible pitfalls of a study of a world-famous fairy tale such as "Cinderella": the ideologically and politically problematic cultural, national, and linguistic reification of the fairy tale, and "equally questionable universalizations of the Cinderella story erasing all differences" (14).

Abandoning the idea of an Urtext, the articles included in the collection refer to versions rather than variants of "Cinderella", and seek difference rather than authenticity or an imaginary origin of a particular text of the tale. Following Homi Bhabha's concept of cultural translation, the editors call for an understanding of the fairy tale that will go beyond the idea of Cinderella/“Cinderella” as a fixed or universal character/text. According to them, the tale in focus is above all transculturally defined and inherently on the move, i.e. constantly transposed, repurposed, reconceived. Following that premise, the studies included in Cinderella across Cultures offer readers interpretations of a variety of forms, genres, cultural and historical contexts, ranging from book format to film, from national to cross-cultural perspectives, from Poland to France, from socialism to consumerism.

The collection consists of eighteen studies framed by and supplemented with a rich peritext: foreword, introduction, illustrations, lists of colour plates, short biographies of contributors, and a detailed index. It should be noted that the studies included in this collection are based on papers initially presented at the 2012 international conference "Cinderella as a Text of Culture" held in Rome at La Sapienza. In the collection, they are assembled in three sections. The first section, entitled "Contextualizing Cinderella", brings together articles on different aspects and specifics of various linguistic, historical, and cultural distributions of "Cinderella". Often starting with the translation or comparison of the two most famous versions of "Cinderella", one written by Charles Perrault and the other included in Jacob and Wilhelm Grimm's renowned collection, and/or their ancestors and successors, the studies published in this section discuss topics such as the influence of individual translators, the dissemination of the fairy tale in penny print, adaptations of fairy tales for children, controversial motifs, etc.

The second section, entitled "Regendering Cinderella", focuses on gender and genre transformations of "Cinderella", i.e. literary rewritings, adaptations of the story written by Margaret Atwood, Angela Carter, Emma Donoghue, Donna Jo Napoli, David Levithan, Babette Cole, etc. Sometimes following new but sometimes also known pathways, this 
section addresses important topics of the submissive and subversive potential of fairy tales and literature in general. The third and final section, "Vizualizing Cinderella", deals with the rich tradition of visual representations of "Cinderella", convincingly broadening the field of research beyond the verbal and the textual. Illustrations, as well as film, theatre, and poster versions of "Cinderella", add analytical scrutiny to the studies in this section.

The studies gathered in this collection predominantly discuss "Cinderella" within a socio-historical vein, but also include the perspectives of other disciplines, such as art history, studies of material culture, etc. This stepping away from the often intriguing but sometimes also predictable argumentation, foci, and themes developed within the sociohistorical branch of fairy-tale studies makes this collection relevant beyond the analysis of this specific fairy tale. It can be assumed, too, that this venturing outside the given context generates a shift away from the sometimes mechanical and merely ornamental taking over of grand concepts and theories, which appears as a side effect of the broadening of interest for one particular approach or field. Contrary to such practice, the studies in this collection primarily base their arguments on microtextual interpretation and engagement, while theoretical pillars are included mostly with a critical eye, sometimes directly in opposition to the findings of the interpretation of literary texts. Therefore, and despite its many famous ancestors, ranging from Alan Dundes' now classic collection of essays and articles about "Cinderella" to canonical monographs such as those by Marian Roalfe Cox or Anna Birgitta Rooth, this collection will certainly find its readers and a place in this rich research field.

Marijana Hameř̌ak

\section{Changes in Children's Literature}

\section{Jessica Straley. 2016. Evolution and Imagination in Victorian Children's Literature. Cambridge University Press. 272 pp. ISBN 978-1-107-12752-4}

DOI: 10.21066/carcl.libri.2017-06(02).0010

The $19^{\text {th }}$ century was a period of great transformations in the British world. The Industrial Revolution brought massive changes in manufacturing techniques, and Charles Darwin fundamentally altered the way of thinking in natural science. Such major developments brought shifts in social engagement for human rights, and, consequently, educational reform. The recently published monograph Evolution and Imagination in Victorian Children's Literature combines interdisciplinary findings and the advancement of scientific fields in the Victorian period to explain children's literature of the time. The author, Jessica Straley, is Assistant Professor of English at the University of Utah with a special interest in Victorian studies - specifically, how evolutionary theory made an impact on literature about and for children.

Evolution and Imagination in Victorian Children's Literature is divided into five chapters in which Straley chronologically explains the evolution of children's literature in accordance with new discoveries in natural science, and the subsequent cultural transformation. Each chapter includes several examples from $19^{\text {th }}$ century children's literature, such as works by Margaret Gatty, C. Kingsley's The Water Babies, L. Carroll's Alice's Adventures in Wonderland, R. Kipling's books about the jungle, or F.H. Burnett's 